\title{
1. Intra-firm trade, embeddedness and international knowledge transfer in the multinational enterprise
}

\author{
Nigel Driffield, James H. Love and Stefano Menghinello
}

\section{INTRODUCTION}

One of the key issues in the literature on innovation and international business is the extent to which the multinational enterprise (MNE) is an effective vehicle for international technology and knowledge transfer. This process is central to the dominant paradigm of the multinational enterprise (Dunning 1979; Buckley and Casson 1976). The paradigm essentially relies on the observation that the single most important determinant of a firm's decision to engage in foreign direct investment (FDI) is its ability to exploit its 'ownership advantages' or firm-specific assets in foreign environments where other options, such as licensing, are less attractive. The ability to transfer knowledge internally across international boundaries is therefore a central element of MNE theory.

Despite some important developments in this literature, relatively little in the empirical literature concerning international technology transfer has changed since Kotabe et al. (2007) noted that "... the study of international knowledge transfer processes within multinational firms is at a relatively early stage" (Kotabe et al. 2007: 259). Instead, much of the literature on international technology transfer has adopted a rather indirect approach to testing the hypothesis that knowledge is transferred within the MNE, and with very imperfect methods. Typically, the testing of this approach within a quantitative setting has sought to determine the relationship between foreign presence in a given location and productivity of host country firms. Where a positive association is found, this is taken as evidence not only of externalities or 'spillovers' from overseas affiliates to domestic firms, but implicitly of the transfer of knowledge from the MNE to its overseas affiliates (for reviews of this literature see Smeets 2008, and Meyer and Sinani 2009).

This emphasis on an indirect approach to assessing inter-firm knowledge transfer is understandable given the difficulties of gathering data on the internal operations of MNEs, but has led to some weaknesses in the literature. First, the emphasis on the spillovers literature tends to be on technology flows, and firm-specific assets have typically become characterised as technological capacity (see for example Cantwell 2009). However, this dismisses a wide range of other firm-specific assets, including managerial knowledge or competence. These are often ignored in the international technology transfer literature, despite these alternative measures of ownership advantage (and potential sources of international knowledge transfer) being discussed in detail in the conceptual analysis (e.g. Caves 1986). Second, the spillovers literature naturally tends to conflate two distinct processes, (international) knowledge transfer between parent and affiliate, and the extent to which this subsequently generates spillovers. At the same time, much of this literature presumes that the source of the 'spillover' is knowledge that is 
generated at the level of the parent, and fails to allow fully for the capacity of subsidiaries to self-generate knowledge even in the absence of intra-firm technology flows (Bell and Marin 2004; Driffield et al. 2010, 2016).

To some extent these problems have been alleviated by research on the 'embeddedness' of multinational affiliates. Conceptual analysis suggests that the nature of the knowledge flows between parent and affiliate depends on the strategic position of the subsidiary and its relative performance (Andersson et al. 2001, 2005, 2007). This literature highlights the importance of both the technological capacity and the success of the subsidiary in explaining subsidiaryparent technology transfer. Typically, however, the existing literature proxies embeddedness using only indirect measures such as the financial performance of the subsidiary We extend this by linking this conceptual literature to explicit measures of the importance of the subsidiary within the parent's supply chain. Specifically, we focus on intra-firm trade, and its relationship to knowledge and technology transfer.

Despite general agreement that it accounts for as much as $40 \%$ of total trade (see Bernard et al. 2010) intra-firm trade is rather under-researched. While the links between international trade and international knowledge flows have been examined (e.g. van Pottelsberghe de la Potterie and Lichtenberg 2001), there is very little consideration of the links between intra-firm trade and intra-firm knowledge transfer which is also international in scope. To the extent that this issue has been considered in the literature, it is invariably as a by-product of analyses of the roles of MNE subsidiaries rather than as a central issue in its own right (Kobrin 1991; Gupta and Govindarajan 1991, 1994; Harzing and Noorderhaven 2006). By contrast, we argue that intra-firm trade is strongly linked to intra-firm knowledge flows, and is an important indicator of how central to the activities of the MNE is a given subsidiary.

In this chapter we therefore put the emphasis back on the direct measurement of intra-firm knowledge flows across national boundaries. In doing so, we explicitly build on the analysis of Driffield et al. (2010). This earlier work focused on an empirical approach to the modelling of international technology transfer and its subsequent diffusion to the host economy that represents an advance on the rather indirect approaches that have been employed hitherto. We extend the existing literature in a number of ways. First, we provide direct evidence of knowledge transfer between MNE parents and affiliates, using a large-scale official survey designed for this purpose. Second, we are able to distinguish between technology and other forms of (managerial) knowledge flows, and so can shed further light on the 'black box' of intra-group and international knowledge transfer. Third, we examine how the characteristics of the MNE and its affiliates are linked to knowledge flows of different types, paying particular attention to the roles of R\&D, knowledge capital, exporting and country of ownership in determining the nature and direction of knowledge flows. Finally, and centrally, we examine the nature of the relationship between intra-firm trade and intra-firm knowledge flows. As indicated above, this is another dimension of embeddedness of the affiliate, and we develop hypotheses relating intra-firm trade to intra-firm knowledge and technology transfer. To the best of our knowledge, this is the first analysis that addresses directly the links between international knowledge transfer and intra-firm trade, and formally tests the nature of the relationship between them.

The remainder of the chapter is structured as follows. The next section outlines the general conceptual model of the MNE as a vehicle for international knowledge transfer, and considers methodological issues relating to the measurement of knowledge flows. The third section develops specific hypotheses from the conceptual and empirical literature relating to intra-firm trade, embeddedness and knowledge transfer. The fourth section describes the dataset. The 
fifth section is concerned with the empirical testing of the hypotheses, and the sixth section concludes.

\section{THE MNE AS A VEHICLE FOR INTERNATIONAL KNOWLEDGE TRANSFER}

At a conceptual level there are (at least) two different perspectives that critically depend on the assumption of international intra-firm knowledge. First, intra-firm knowledge transfer is important per se within the framework of knowledge economics to corroborate the role of the hierarchy in general, and MNEs in particular, as a superior vehicle of knowledge transfer and diffusion with respect to arm's length market forces under uncertainty and other market failure conditions. Second, intra-firm knowledge transfer is important with the classical OLI approach to the theory of the MNE as indirect evidence of the superior competitive advantage of MNEs over domestic firms. Reverse knowledge flows (i.e. from affiliate to parent) are not in conflict with an enlarging view of the classical paradigm where MNEs do not necessarily hold a superior technological advantage, but where they do have a superior capability to coordinate knowledge flows internationally.

In extending our earlier work (Driffield et al. 2010), we offer a simple schematic of the traditional view of international knowledge transfer, as shown in Figure 1.1. At its simplest, the process first requires knowledge transfer from the MNE to its foreign affiliate (A1) followed by the potential for the generation of externalities (i.e. spillovers) from the foreign affiliates to domestic firms (A2). In practice, there is no guarantee that either condition A1 or A2 will be fulfilled. Not all affiliates automatically have access to the leading technology of their parent company, and, notwithstanding the possibility of inadvertent leakage, multinational enterprises frequently go to considerable lengths to internalise their knowledge and prevent or control its transfer to third parties. Therefore, even if intra-firm knowledge transfer occurs, there is no guarantee that the domestic economy in which the affiliate is located will benefit as a result. For example, in a study of MNE subsidiaries in Belgium, Veugelers and Cassiman (2004) find that, after controlling for their superior access to international technology, foreign subsidiaries are no more likely than local firms to transfer technology to the domestic economy. Going even further, Singh (2007) uses patent citation data to trace knowledge flows between MNEs and host country organisations in 30 countries, and concludes that there is a substantially higher likelihood of knowledge flows running from domestic entities to multinational subsidiaries than the reverse.

In recent years, a number of studies have questioned the conventional view of knowledge spillovers from parent MNEs to domestic host economies, channelled through foreign affiliates. Much of this has come from the recognition that the nature of the relationship between parent and affiliate, and between affiliate and the domestic economy, can be very flexible and mutually dependent. This frequently includes a substantial role for localised innovative activity at the affiliate level, and a substantial literature has developed on the internationalisation of $\mathrm{R} \& \mathrm{D}$ and its role in technology sourcing by MNEs.

For example, evidence suggests that corporations are increasingly moving their R\&D facilities abroad, and that this is being done as part of a strategic move away from merely adapting 'core' technology to a foreign market towards a much more central role in product innovation and development. Companies that previously exerted rather tight control over their 


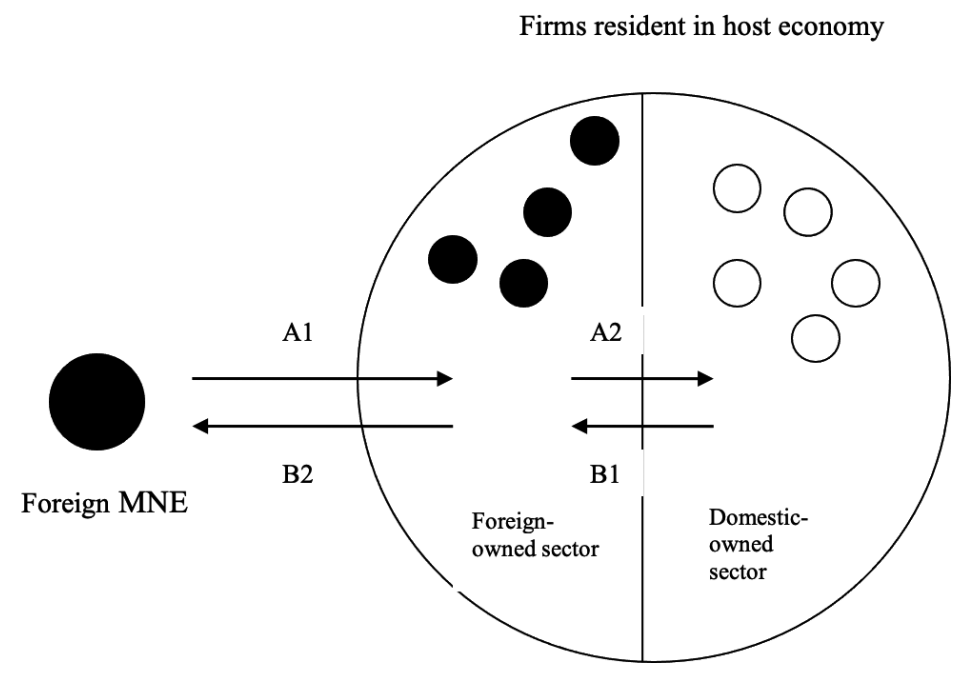

Figure $1.1 \quad$ Conceptual scheme of knowledge flows

R\&D sites are now granting more autonomy and empowerment to R\&D laboratories situated abroad (Cantwell and Janne 1999). This literature suggests that in the 1970s and early 1980s organisations saw establishing R\&D outlets abroad as little more than adapting products to local markets as hypothesised by the product life cycle hypothesis. However, during the 1990s, organisations began to take a more decentralised approach to R\&D (Pearce 1999; Niosi 1999). In addition, the literature suggests that there is a growing willingness to locate such facilities close to leading centres of research and innovation, specifically with a view to absorbing learning spillovers from geographical proximity to such sites (Serapio and Dalton 1999; Ito and Wakasugi 2007). The possibility of this form of technology sourcing FDI depends on the existence of 'reverse spillovers' in which an externality effect runs from the domestic sector to MNE affiliates, support for which comes from Driffield and Love (2003). In terms of Figure 1.1 , the reverse spillover effect is flow B1. To complete the process, knowledge transfer then occurs between the foreign affiliate and the parent company (B2). ${ }^{1}$

However, even the consideration of technology sourcing may underestimate the complexity of knowledge flows within MNEs and their associated spillover effects. Driffield et al. (2016), for example, highlight the contributions of Bell and Marin (2004), Marin and Bell (2006, 2010) and Mudambi and Navarra (2004). The former suggests that the role of affiliates in both knowledge creation and dissemination has been under-stated, while the latter highlight the nature of the potential agency problem this creates for the parent. As such, Driffield et al. (2016) develop a framework that considers knowledge transfer to be neither automatic nor a sufficient condition for generating increased performance at the level of the firm. We argue, therefore, that one needs to better understand the precise nature and drivers of knowledge transfer between parents and affiliates, and develop better models for capturing this. In turn, as Bell and Marin (2004) point out, this requires both better data and models more closely linked to theories of knowledge transfer and international business. They subsequently argue that even if there is statistical evidence of productivity increases among domestic firms where FDI is high, these need not stem from technology at the MNE's centre; they may result from 
technology developed directly by the affiliates, or from bi-directional spillovers between affiliates and the parent company. Indeed, the wider literature suggests that apparent host country productivity growth linked to FDI may be a result of other effects of FDI, such as competition, market structure or demand effects (Driffield et al. 2002). Bell and Marin (2004) develop an alternative to the standard 'centrally driven supply-side model', in which technology flows from MNE centre via subsidiaries to local firms via competition effects or through real or pecuniary spillovers. This alternative model allows for locally based and locally driven sources of spillovers in which affiliates play a crucial role in knowledge generation and development, so that knowledge either comes directly from the affiliates' innovation activity via spillovers to domestic firms, or they modify and enhance the knowledge coming from the centre in some way which improves the chances of knowledge-based productivity spillovers. Taken together therefore, we argue, and demonstrate here, that we need more direct indicators of knowledge transfer, as well as a better understanding of relationships between affiliates and parents (or between affiliates) at the level of the multinational.

This conceptual and empirical work suggests that the nature of the knowledge flows between parents and affiliates is crucial in determining both the affiliates' capacity for generating its own innovative activity, and the affiliates' ability to generate knowledge flows to local firms (see also Oh and Anchor 2017). In the Bell and Marin model, the externality effect of FDI (A2) is not necessarily dependent on knowledge flows from the parent (A1), and there is an enhanced role for two-way knowledge flows between the parent and affiliate (i.e. A1B2). Importantly, this suggests that the existence or otherwise of intra-firm knowledge flows between an MNE and its affiliates cannot simply be inferred from the existence of spillover effects.

This in turn indicates the importance of obtaining more direct evidence on the nature and scale of the knowledge flows between affiliates and their parent companies. Semi-direct data on knowledge flows such as patent citations have helped our understanding of the process of technology transfer (Almeida 1996; Singh 2007; Phene and Almeida 2008). While this represents a significant step forward in this area, such analysis is still reliant on inferring intra-firm international technology transfer from links between knowledge stocks and patent citations, and ultimately employs a data source that is not gathered explicitly for the purpose to which it is being put. Veugelers and Cassiman (2004) seek to move towards a more direct approach towards prising open the 'black box' of knowledge transfer rather than relying wholly on inferring such flows from their indirect impact on local productivity. The empirical study below further helps to fill this gap by analysing knowledge flows involving foreign affiliates operating in Italy. Like Veugelers and Cassiman, this relies on direct survey evidence on knowledge flows, a crucial step in breaking the direct inferential link between spillover effects and the existence of the knowledge flows that are assumed to underlie them

\section{KNOWLEDGE TRANSFER AND THE MNE SUBSIDIARY: THEORY AND HYPOTHESES}

Foreign affiliates differ in the extent to which they play certain roles within the MNE, most importantly varying by strategic importance within the parent firm. Conceptual and empirical analysis suggests that the nature of the knowledge flows between parent and affiliate depends on the strategic position of the subsidiary and its relative performance (Andersson et al. 2001, 
2005, 2007). This literature stresses that the more strategically important a subsidiary is to the parent, the more likely it is to be both a source and a recipient of technology and of other forms of knowledge. The existence of intra-firm knowledge flows therefore signals both the strategic importance and embeddedness of a foreign affiliate in the MNE's network.

However, empirical work in the area has largely lagged behind the conceptual analysis. In a review paper, Michailova and Mustaffa (2012) discuss many of the limitations in this literature, highlighting the fact that much of it focuses on the outcomes of knowledge flows, and typically, often due to data limitations, only in one direction, i.e. either from subsidiary to parent or from parent to subsidiary. This in turn suggests a disconnect between the conceptual embeddedness literature (e.g. Andersson et al. 2001) which focuses on the importance of multiple sources of embeddedness, and the empirical literature which, possibly due to a paucity of data, focuses on a limited number of sources. Michailova and Mustaffa (2012) highlight the need for research on flows both to and from subsidiaries, and the need for better theoretical underpinnings, linked to, for example, an explanation of how individual variables or constructs are linked to knowledge flows. A recent example of this is the work by McGuinness et al. (2013), who develop a more holistic multi-perspective model of knowledge transfer, but again are then limited to knowledge flows from subsidiary to parent. Equally, in common with the work by Rabiosi (2011), they are also limited by data availability in the extent to which they can control for differences in the nature of interactions between subsidiaries and their local environment.

The existing literature typically proxies embeddedness using only indirect measures such as the financial performance of the subsidiary. Ciabuschi et al. (2011) study how important internal networks, and associated embeddedness, are for innovation. They focus on the extent to which affiliate embeddedness into the parent determines how they create competitive advantage. They argue that embeddedness of subsidiaries drives competitive advantage through innovation at the level of the parent, arguing that one must view the network of subsidiaries, and their relation with the parent, through the lens of business network analysis. As they also go on to suggest, this requires further work and refinement in terms of understanding the nature of the relationships between parent and affiliate, and the form that this embeddedness takes. In a further interesting contribution, Rabiosi and Santangelo (2013) highlight the importance of organisational ecology in explaining variations in knowledge flows from subsidiary to parent. The focus of their subsequent analysis is the age of the subsidiary. We extend this by linking this conceptual literature to explicit measures of the importance of the subsidiary within the parent's supply chain. Specifically, we focus on intra-firm trade, and its relationship to knowledge and technology transfer.

In order to develop a more coherent analysis of international knowledge transfer, we build on Driffield et al. (2010) and seek to distinguish conceptually the different mechanisms by which international technology and knowledge transfer occur, and determine how such transfer may be identified empirically. Some existing typologies exist from the literature on subsidiary evolution and control. For example, Gupta and Govindarajan $(1991,1994)$ view the multinational enterprise as a network involving flows of knowledge, capital and goods. They argue that knowledge flows are the most important of these, and develop a typology of subsidiaries based around the nature (direction and extent) of internal knowledge flows within the MNE. Four categories of MNE subsidiary are identified: global innovators (high outflows of knowledge, low inflows); integrated players (high outflows, high inflows); implementors (low outflows, high inflows); local innovators (low outflows, low inflows). 
Our concern is with the direct measurement and analysis of knowledge flows within the MNE, i.e. with flows A1 and B2 in Figure 1.1. Consistent with the analysis of Gupta and Govindarajan and the related literature (e.g. Kobrin 1991; Birkenshaw and Morrison 1995; Harzing and Noorderhaven 2006), four mutually-exclusive combinations of knowledge flows can be conceptualised.

Type 1: Two-way flows. Knowledge flows in both directions between the parent and/or other units and its foreign affiliate. This is a fully embedded affiliate within the MNE network, and is consistent with Gupta and Govindarajan's integrated players.

Type 2: Parent-affiliate flows. Knowledge flows only from parent to affiliate. This can be thought of as standard 'knowledge exploiting' behaviour within Dunning's OLI framework, in which an MNE exploits its superior knowledge in a host country by transferring the knowledge to its foreign affiliate. This is consistent with Gupta and Govindarajan's implementors, subsidiaries heavily dependent on knowledge inflows but which play relatively little role in knowledge creation.

Type 3: Affiliate-parent flows. Knowledge flows only from affiliate to parent and/or other organisational units. This may occur either because the affiliate is a research establishment set up for that purpose, or because it is a 'listening post' designed to source knowledge from the local economy. Each of these (non-mutually exclusive) cases can be thought of as a form of 'knowledge sourcing' activity. This is consistent with Gupta and Govindarajan's global innovators, which are "... a fountainhead of knowledge for other units" (Harzing and Noorderhaven 2006: 197).

Type 4: No knowledge flows. There are no knowledge flows between the parent and affiliate. This is consistent with Gupta and Govindarajan's local innovators; these are subsidiaries which are self-standing and which may be involved in knowledge creation, but from which there is no knowledge transfer to other organisational units. It may also occur where the affiliate forms no knowledge linkages with either the MNE of which it is part, or with other international actors. In a study of MNE affiliates in Argentina, Marin and Giuliani (2011) found this form of 'globally isolated' affiliate to be relatively common.

This typology of knowledge flows can be related to the extent to which the affiliate is embedded within the MNE network. Further, since the central strategic assets of MNEs are often managerial rather than technological, the conceptual analysis should allow for flows of managerial knowledge as well as technology within the MNE. The next stage is to link key characteristics of the MNE and its affiliate relationships to the four types of knowledge flows outlined above. We discuss in turn the roles of intra-firm trade, R\&D and knowledge assets, and subsidiary exporting.

\section{The Importance of Intra-firm Trade in International Technology Transfer}

There are conceptual reasons for linking intra-firm trade to intra-firm knowledge transfer. Davidson and McFetridge (1985) show that the same firm-specific assets that facilitate FDI within the standard OLI paradigm of international business also facilitate intra-firm trade. They suggest that for reasons of transaction-cost minimisation and property rights protection, intra-firm trade will tend to be associated with the core technology of the firm, while more 
peripheral technologies, or the products that they embody, will be traded outside the firm. Cho (1990) advances this literature by examining the product-specific factors of intra-firm trade. In a study of US manufacturing multinationals, Cho shows that that knowledge intensity is indeed strongly associated with intra-firm trade at the product level, implicitly supporting the conceptual analysis of Davidson and McFetridge (1985).

This suggests that there is a link between intra-firm knowledge and trade flows, as there is between flows of trade and of knowledge internationally. Just as trade and investment are both seen as important vehicles for market-based technology and knowledge transfer between countries, intra-firm trade is an important indicator of links between a firm's subsidiaries, and of how central to the activities of the MNE is a given subsidiary. For example, Kobrin (1991) suggests that intra-firm trade is likely to be an indicator of knowledge flows within the firm, and thus of the extent to which the MNE is managed in a globally integrated manner. Feinberg and Gupta (2004) make the same inference in their analysis of the determinants of R\&D location in foreign subsidiaries, arguing that since intra-firm trade is likely to involve intermediate and semi-finished products, it requires the existence of relatively well-developed communication and knowledge-exchange structures within the MNE. However, Feinberg and Gupta do not test this assumption, simply using it as the basis on which to develop the hypothesis that the likelihood of a subsidiary having an R\&D function is positively related to the magnitude of intra-firm trade (which they find to be weakly supported in an analysis of R\&D capacity among MNE affiliates in 11 OECD countries). ${ }^{2}$

In general, therefore, we expect a positive relationship between intra-firm trade and intra-firm knowledge flows: both are indicators of the strategic importance of the affiliate to the MNE, and are markers of the degree of embeddedness of the affiliate.

This analysis can be extended to the nature of knowledge flows and their relationship with intra-firm trade, allowing us to develop hypotheses linked to the four-way classification of affiliates outlined above. If Davidson and McFetridge (1985) are correct in their assertion that that intra-firm trade will tend to be associated with the core technology of the firm, then we would expect to see intra-firm trade closely associated with technology exploiting knowledge flows (where the parent transfers internally core technology and knowledge to the affiliate) and with two-way flows, because these indicate a high degree of embeddedness of the affiliate in the MNE network. By contrast, technology sourcing knowledge flows implies a situation where the affiliate is a research establishment or a 'listening post' designed to source knowledge from the local economy. Knowledge flows in this case are likely to comprise technology or other knowledge which is not yet core to the MNE activity, and is therefore unlikely to be associated with intra-firm trade. Consistent with this, in their empirical analysis of Gupta and Govindarajan's (1991) typology, Harzing and Noorderhaven (2006) hypothesise that integrated players and implementors (i.e. Types 1 and 2 above) will display relatively high levels of intra-firm product flows (i.e. intra-firm trade), a finding which is supported in their empirical analysis of 169 MNE subsidiaries. ${ }^{3}$ Birkenshaw and Morrison (1995) also find a similar pattern of intra-firm imports among their equivalents of Types 1 and 2 . This is consistent with the theoretical underpinnings of internalisation theory, building on Buckley and Casson (1976). This takes the firm as the unit of analysis, and seeks to explain how the firm determines its boundaries, and subsequently how it allocates activities, given the strategic and managerial resources that are available to it. Intra-firm trade is therefore an important indicator of the ability of the firm to manage and coordinate activities across countries. Further, it is an 
indicator of the nature of the internalisation that the firm has undertaken, with potential links to the drivers of location in the firm, and the embeddedness literature discussed above.

This leads to the following hypotheses:

H1: Intra-firm trade is positively associated with parent-affiliate and two-way knowledge flows, both technological and managerial.

H2: Intra-firm trade is unrelated to affiliate-parent technological or managerial knowledge flows.

\section{R\&D and Knowledge Assets}

The availability of knowledge-based assets has long been central to the theory of the MNE. Our concern here is specifically with the knowledge assets available to MNE affiliates, and how these relate to the flows of knowledge and technology between the affiliate and its parent organisation.

R\&D intensity of the affiliate is an indicator not only of subsidiary performance, but also of how the subsidiary is viewed strategically by the parent. Cohen and Levinthal (1989) stress that R\&D capacity has two dimensions: it contributes directly to innovation and knowledge creation, and also forms the basis for absorptive capacity, permitting technology and knowledge to be absorbed from elsewhere. The absorptive capacity element of R\&D provides the subsidiary with the capacity to absorb knowledge from the parent, and elsewhere within the MNE. However, this capacity can also be used to source and channel technology from host economies. The literature on the internationalisation of R\&D suggests that there is a growing willingness to locate affiliate $R \& D$ facilities close to leading centres of research and innovation specifically with a view to absorbing learning spillovers from geographical proximity to such sites (Serapio and Dalton, 1999; Ito and Wakasugi 2007). Here, affiliate-level R\&D provides the basis for technology sourcing from the host economy and subsequent transfer back to the parent. Thus, the absorptive capacity element of R\&D provides the capacity for two-way flows of technology, both from parent to affiliate but also for transfers from affiliate to parent via technology sourcing from the host economy.

As described by Cohen and Levinthal (1989), R\&D also has a strong direct effect on innovation and knowledge creation. In the context of the MNE, affiliate R\&D and knowledge assets thus provide not only the capacity to absorb technology from the parent MNE and from the host economy, but also potentially the basis for affiliate's self-generated technology flows back to the parent even where technology flows from the parent are limited or absent (Type 3). Bell and Marin (2004) and Marin and Bell (2006) illustrate not only that such an effect may exist, but that it arises not merely from the R\&D capacity of affiliates, but also from their investment in capital-embodied technology, mainly through intangible knowledge assets. However, there is less reason to expect this R\&D effect to be present in managerial (rather than technological) knowledge flows, which are less likely to be based on the results of formal R\&D activity. This discussion of the dual role of $R \& D$ and knowledge assets leads to the following hypotheses:

H3a: Affiliate investment in $R \& D$ and knowledge capital is positively associated with two-way technology flows and with affiliate-parent technology flows. 
H3b: Affiliate investment in knowledge capital is positively associated with two-way and with affiliate-parent managerial knowledge flows.

While R\&D is an important dimension of technology flows from affiliates to parents, by contrast, R\&D-intensive and knowledge capital-intensive subsidiaries are relatively unlikely to be the recipients of one-way technology flows from parent companies (Type 2). An MNE is unlikely to invest heavily in the R\&D capacity of an affiliate merely to channel technology from parent to affiliate. There may, of course, be some need for adaptation, but this does not normally require a high level of R\&D intensity. This is especially true of relatively advanced host economies, in which there is typically relatively little need for technology adaptation before parental technology can be applied to the local market. As a result, the standard 'technology exploiting' transfers (Type 2 flows) are more likely to occur with respect to relatively less-R\&D and knowledge-capital intensive subsidiaries. This leads to the next hypothesis:

H4: Affiliate investment in $R \& D$ and knowledge capital is negatively related to one-way parent-affiliate technology flows.

\section{Exporting}

As discussed in Driffield et al. (2010), the role of the affiliate with respect to exports is also important. There is strong evidence that firms entering export markets must first develop the capabilities required to compete in highly competitive international markets (Wagner 2007). In the case of MNE affiliates, even where an affiliate is initially a platform for exports built on technology derived from the parent, the affiliate may develop capabilities derived from exporting which can then serve as a possible source of knowledge flows back to the parent. This is consistent with the 'learning by exporting' hypothesis, in which exposure to the knowledge stocks of trading partners improves the firm's own knowledge and ultimately leads to performance improvement, especially in conjunction with R\&D (Aw et al. 2008). Support for this hypothesis comes from Ito and Wakasugi (2007), who find that a high propensity to export is associated with a greater incidence of technology sourcing R\&D among Japanese overseas subsidiaries. We therefore expect export intensity to be positively related to knowledge-sourcing behaviour: the exporting effect is hypothesised to be relevant to both technology and managerial knowledge flows.

H5: Export intensity is positively related to affiliate-parent knowledge flows, and negatively to one-way parent-affiliate knowledge flows.

\section{Conditioning Variables}

We also include a number of conditioning variables which may affect the nature of intra-MNE knowledge flows. We have no specific priors with respect to these variables, and regard them as conditioning variables. First, we allow for size of affiliate (by turnover) and its square. Second, we allow for affiliate performance in terms of profitability and productivity. As Andersson et al. $(2001,2005,2007)$ point out, these aspects of performance are alternative 
indicators of the embeddedness of the affiliate, which may in turn be linked to knowledge flows. Failure to allow for performance variables could result in omitted variable bias and inaccurate coefficients on other key variables. Finally, we include dummy variables for the type of industry and parent country ${ }^{4}$ of the MNE (see Tables 1.1 and 1.2).

\section{Table 1.1 Sample distribution by industry classification}

\begin{tabular}{llrr}
\hline Industry code & Description of the industry & No. & Percent \\
\hline HTI & High technology industries & 85 & 11.18 \\
MHTI & Medium-high technology industries & 303 & 39.87 \\
MLTI & Medium-low technology industries & 167 & 21.97 \\
LTI & Low technology industries & 115 & 15.13 \\
HTKIS & Knowledge intensive high technology services & 90 & 11.84 \\
Total & & 760 & 100.00 \\
\hline
\end{tabular}

Note: Based on the OECD-EUROSTAT classification of high-technology industries and knowledge-intensive services

Table $1.2 \quad$ Sample distribution by geographical area of foreign control

\begin{tabular}{llrr}
\hline Country/Area code & Description of the geographical area & No. & Percent \\
\hline US & United States & 190 & 25.0 \\
EU & European Union & 439 & 57.8 \\
JP & Japan & 19 & 2.5 \\
OC & Others & 112 & 14.7 \\
Total & & 760 & 100.0 \\
\hline
\end{tabular}

\section{DATA AND DESCRIPTIVE STATISTICS}

The empirical part of this chapter exploits a unique dataset at the firm level produced by ISTAT (the Italian National Statistical Institute) for a large sample of foreign affiliates resident in Italy. This was part of an official survey of over 6500 foreign affiliates within the framework of an EU Regulation, which had a census nature for large and medium size companies (50+ employees) and a random nature (stratified by industry) for small businesses. ${ }^{5}$ The questionnaire was addressed to top management positions (e.g. CEO, chief accounting officer) in the company; reply was mandatory under Italian law. The sample considered here focuses on manufacturing and high-technology services for a total of 760 companies. ${ }^{6}$ Tables 1.1 and 1.2 show the distribution of firms in the sample by technological sector and country ownership.

The dataset combines standard quantitative data with unique information on Italian resident foreign affiliates. These are derived by linking the official survey on foreign affiliates with several other official surveys, including those based on company accounts, foreign trade in goods, and R\&D. All variables originate from official surveys whose samples were drawn from the Italian business register set up and maintained by ISTAT, and are collected with respect to the same reference year and linked through the business register identification code. This guarantees the full consistency of the results. All variables, except those on knowledge transfer, are standard OECD measures as adopted by ISTAT.

Data on knowledge transfer within the MNE were collected by ISTAT in a special section of the questionnaire of the Italian survey on resident enterprises under foreign control. This 
was part of a study promoted by the OECD on the role played by foreign MNEs for the domestic economy. In particular, two questions were explicitly designed to focus on knowledge transfers between the foreign affiliates and their parent companies. These questions were formulated in a way that is consistent with the theoretical debate introduced in the previous sections, and are concerned with flows A1 and B2 of Figure 1.1. These discrete variables convey evaluations made by managers working in foreign affiliates. The first question refers to international technology transfer between the parent company and their Italian affiliates. This question considers both the nature and the direction of the scientific or technical knowledge transfer. ${ }^{7}$ The second question relates to the nature and direction of the transfer of managerial, commercial and other types of competencies. ${ }^{8}$ In both cases the direction of flow distinguishes between the flow from the Italian affiliate to the parent (affiliate-parent transfer), and the opposite (parent-affiliate transfer).

Table 1.3 shows the breakdown of intra-firm knowledge flows by category of affiliate as established earlier. Intra-group knowledge transfer is widespread in the sample, with $56.0 \%$ $(61.2 \%)$ of affiliates experiencing some form of technology (managerial) transfer from their parent, roughly evenly split between two-way (Type 1) and parent-affiliate only (Type 2) flows. Perhaps more surprisingly, knowledge transfer from affiliates to parents is also relatively common, experienced by $31.2 \%$ of affiliates in terms of technology, and $31.6 \%$ in terms of other managerial knowledge. However, the vast majority of this takes place as part of a two-way process: one-way transfers from affiliate to parent (Type 3) are experienced by only $6 \%$ of affiliates. This does not necessarily imply that technology sourcing by affiliates is uncommon, simply that it generally occurs as part of a two-way process. Around one third of affiliates in the sample experience no knowledge flows with the parent.

Table $1.3 \quad$ Pattern of knowledge transfer by category of affiliate

\begin{tabular}{lrrrr}
\hline Type of flows & Intra-group technology transfer & \multicolumn{2}{c}{ Intra-group managerial transfer } \\
\hline & No. & Percent & No. & Percent \\
\hline 1. Two-way flows & 236 & 31.0 & 270 & 35.5 \\
2. Parent-affiliate only & 190 & 25.0 & 195 & 25.7 \\
3. Affiliate-parent only & 47 & 6.2 & 45 & 5.9 \\
4. No knowledge flows & 287 & 37.8 & 250 & 32.9 \\
Total & 760 & 100 & 760 & 100 \\
\hline
\end{tabular}

Overall, therefore, the pattern is of extensive knowledge transfer between parents and affiliates, predominantly, but not overwhelmingly, running from parents to affiliates, with a substantial two-way element. This affords some contrast with the secondary patent citation analysis of Singh (2007), which suggests that the likelihood of knowledge flows between MNEs' home base and their foreign subsidiaries are very similar in both directions.

Table 1.4 shows the pattern of foreign trade, intra-firm trade and R\&D activity broken down by industry grouping. Around one quarter of affiliates in the sample engage in R\&D activity, with a predictable pattern with respect to technological intensity. By contrast, the vast majority of plants engage both in international trade and in intra-firm trade. Even affiliates involved in knowledge-intensive services are substantially involved in international and intra-firm trade, albeit to a markedly lesser extent than manufacturing affiliates in the sample. 
Table $1.4 \quad$ Foreign affiliates in Italy engaged in trade and $R \& D$ activity by industry category (percent of the total)

\begin{tabular}{|c|c|c|c|c|c|}
\hline \multirow[b]{2}{*}{ Industry code } & \multicolumn{2}{|c|}{ Exports of goods and services } & \multicolumn{2}{|c|}{ Imports of goods and services } & \multirow[t]{2}{*}{$\mathrm{R} \& \mathrm{D}$} \\
\hline & Total & Intra-firm & Total & Intra-firm & \\
\hline High technology industries & 92.94 & 88.24 & 95.29 & 85.88 & 31.76 \\
\hline Medium-high technology industries & 93.40 & 79.21 & 87.79 & 70.96 & 36.96 \\
\hline Medium-low technology industries & 92.81 & 76.65 & 93.41 & 77.25 & 14.97 \\
\hline Low technology industries & 85.22 & 63.48 & 83.48 & 60.87 & 15.65 \\
\hline $\begin{array}{l}\text { Knowledge intensive high technology } \\
\text { services }\end{array}$ & 58.89 & 44.44 & 68.89 & 56.67 & 11.11 \\
\hline Total & 87.89 & 73.16 & 86.97 & 70.79 & 25.26 \\
\hline
\end{tabular}

\section{DETERMINANTS OF KNOWLEDGE FLOWS}

\section{Model and Estimation}

A multinomial logit model (MNLM) is used to link different patterns of MNE behaviour in terms of knowledge transfer and diffusion to a set of explanatory variables. Within this analytical framework, each of the four types of MNE affiliate identified earlier identifies a specific category of a nominal outcome and it is compared, in terms of probability, to the other categories. These relative probabilities, called odds ratios, are then expressed as a non-linear function of the explanatory variables. Under the assumption that the non-linear function is exponential, the model can be written as the following system of four equations:

$$
\ln \Omega_{m \mid b}(\mathbf{x})=\ln \frac{\operatorname{Pr}(y=m \mid \mathbf{x})}{\operatorname{Pr}(y=b \mid \mathbf{x})}=\mathbf{x} \beta_{m \mid b} \quad \text { for } m=1 \text { to } 4
$$

where $\mathbf{x}$ is the vector of explanatory variables, $\beta$ the relative coefficient to be estimated and $b$ the base category, which is also referred to as the comparison group. The system of four equations (1.1) can be solved to compute the predicted probabilities:

$$
\operatorname{Pr}(y=m \mid \mathbf{x})=\frac{\exp \left(\mathbf{x} \beta_{m \mid b}\right)}{\sum_{J=1}^{4} \exp \left(\mathbf{x} \beta_{j \mid b}\right)}
$$

In particular, errors in the logit model are assumed to follow the standard logistic distribution:

$$
\lambda(\varepsilon)=\frac{e^{z}}{\left(1+e^{z}\right)^{2}}
$$

In addition, the MNLM makes the standard assumption known as the independence of irrelevant alternatives (IIA). Given the following equation:

$$
\ln \Omega_{m \mid b}(\mathbf{x})=\ln \frac{\operatorname{Pr}(y=m \mid \mathbf{x})}{\operatorname{Pr}(y=b \mid \mathbf{x})}=\mathbf{x} \beta_{m \mid b}
$$

This assumption requires that the odds do not depend on other outcomes that are available, in effect assuming that additional outcomes are irrelevant. The IIA assumptions can be tested either by the Hausman and McFadden (1984) test or by the McFadden et al. (1976) test, the latter being improved by Small and Hsiao (1985). Nevertheless, these tests often give inconsistent results and provide little guidance to violations of the IIA assumption. The parameters 
of the MNLM are usually estimated by a maximum-likelihood estimator. Robust error estimators are adopted to cope with heteroscedasticity.

The independent variables in the MNLM estimation comprise the sector and home country categories outlined earlier (Tables 1.1 and 1.2), and a series of quantitative variables derived from the survey. The variables selected are those which the conceptual and empirical literature suggests are most likely to distinguish between the different types of affiliate. In particular, we pay attention to intra-firm trade, $R \& D$ and other knowledge capital intensity, and exporting. Finally we allow for size of affiliate (by turnover) and its square, and for affiliate performance variables (profitability and productivity). As indicated earlier, we have no specific priors with respect to these variables, and regard them as conditioning variables along with the industry and parent-country dummies outlined earlier. Descriptive statistics for the affiliate-level independent variables are provided in Table 1.5a, and a correlation matrix in Table 1.5b.

Table 1.5a Summary statistics on quantitative variables

\begin{tabular}{|c|c|c|c|c|c|}
\hline Variable & Description (a) & Mean & Std. Dev. & Min & Max \\
\hline SIZE & Turnover & 10.07 & 1.88 & 3.04 & $\overline{16.28}$ \\
\hline SIZE2 & Turnover squared & 104.89 & 36.80 & 9.27 & 265.09 \\
\hline TFA & Tangible fixed assets & 14.66 & 2.71 & 0.00 & 19.68 \\
\hline IFA & Intangible fixed assets & 12.16 & 3.61 & 0.00 & 21.06 \\
\hline$R \& D$ & $R \& D$ expenditure & 1.76 & 3.16 & 0.00 & 11.60 \\
\hline PROF & Profitability & 0.10 & 0.12 & -0.42 & 1.46 \\
\hline TFP & Total factor productivity & 0.00 & 0.53 & -2.22 & 2.72 \\
\hline TE & Total exports of goods and services & 7.69 & 3.71 & 0.00 & 14.52 \\
\hline TI & Total imports of goods and services & 7.23 & 3.64 & 0.00 & 13.74 \\
\hline IE & Intra-firm exports of goods and services & 5.77 & 4.09 & 0.00 & 13.57 \\
\hline II & Intra-firm imports of goods and services & 5.40 & 4.08 & 0.00 & 13.74 \\
\hline
\end{tabular}

(a) variables in log, unless expressed as shares

Table $1.5 b \quad$ Correlation matrix

\begin{tabular}{|c|c|c|c|c|c|c|c|c|c|c|c|}
\hline & SIZE & SIZE2 & TFA & IFA & $R \& D$ & TFP & PROF & $\mathrm{TE}$ & $\mathrm{TI}$ & IE & II \\
\hline SIZE & 1.0000 & & & & & & & & & & \\
\hline SIZE2 & 0.9885 & 1.0000 & & & & & & & & & \\
\hline TFA & 0.7452 & 0.7326 & 1.0000 & & & & & & & & \\
\hline IFA & 0.5553 & 0.5590 & 0.5142 & 1.0000 & & & & & & & \\
\hline$R \& D$ & 0.4201 & 0.4417 & 0.3686 & 0.3342 & 1.0000 & & & & & & \\
\hline TFP & 0.2695 & 0.2417 & -0.0000 & -0.0000 & -0.0184 & 1.0000 & & & & & \\
\hline PROF & -0.2716 & -0.2400 & -0.1313 & -0.0983 & -0.0795 & 0.3921 & 1.0000 & & & & \\
\hline TE & 0.7004 & 0.6837 & 0.6216 & 0.3719 & 0.3975 & 0.0689 & -0.1865 & 1.0000 & & & \\
\hline TI & 0.6953 & 0.6871 & 0.5502 & 0.3237 & 0.2868 & 0.1969 & -0.2229 & 0.6346 & 1.0000 & & \\
\hline IE & 0.5559 & 0.5468 & 0.4898 & 0.2973 & 0.3307 & 0.0192 & -0.1521 & 0.7432 & 0.5256 & 1.0000 & \\
\hline II & 0.4983 & 0.4969 & 0.3728 & 0.1998 & 0.1678 & 0.0864 & -0.2075 & 0.4318 & 0.7322 & 0.5826 & 1.0000 \\
\hline
\end{tabular}




\section{Results}

Tables 1.6 and 1.7 show the results of the MNLM estimations for intra-group technology and managerial knowledge flows respectively, based on the four-way affiliate typology discussed above. In each case the coefficients of the model are expressed as log-odds ratios, ${ }^{9}$ relative to the base category (Type 4 - no knowledge flows).

The coefficients on the intra-firm trade variables show a very clear pattern. Intra-firm trade, from parent to affiliate, is positively associated with parent-affiliate and with two-way technology (Table 1.6) and managerial (Table 1.7) knowledge flows. H1 is thus supported. Interestingly, intra-firm imports are more strongly associated with intra-firm technology transfer than are intra-firm exports, ${ }^{10}$ a finding also noted by Harzing and Noorderhaven (2006). However, as with other studies in the area, Harzing and Noorderhaven do not distinguish between flows of technology and flows of other managerial knowledge. Our results indicate that, in the case of managerial knowledge flows, both intra-firm imports and exports are strongly linked to flows for Type 1 and Type 2 subsidiaries, whereas for flows of technology only intra-firm imports have a statistically significant effect. There is no evidence of any intra-firm trade relationship with either technology or managerial knowledge flows in the case of Type 3 (knowledge sourcing) affiliates. Intra-firm exports from subsidiaries are therefore not a crucial vehicle for international technology sourcing, consistent with H2.

As anticipated, therefore, flows of disembodied knowledge and flows of goods and services are closely linked within the MNE, but only where there is evidence of knowledge transfer from parent to subsidiary, either one-way (Type 2) or two-way (Type 1). This suggests that affiliates which are embedded into the parents' (physical) supply chain are more likely to receive and impart flows of new knowledge than those which are not: intra-firm trade is indeed an indicator of embeddedness.

By contrast, once allowance is made for the influence of intra-firm trade, the link between affiliates' R\&D and knowledge flows is relatively modest. R\&D intensity markedly lessens the likelihood of the affiliate simply being a vehicle for technology exploitation via one-way transfers from the parent (Table 1.6). This suggests, as hypothesised (H4), that standard 'technology exploiting' transfers (Type 2 flows) are more likely to occur with respect to relatively less-R\&D-intensive subsidiaries. However, there is no evidence of any relationship between affiliate investment in R\&D and technology or knowledge flows from affiliate to parent. Instead, the source of both technology and managerial knowledge flows in Type 3 (knowledge sourcing) subsidiaries is intangible fixed assets, which is the affiliates' investment in knowledge capital other than R\&D. There is therefore only partial support for H3a and H3b: affiliate-level R\&D does not increase the likelihood of technology flows from affiliate to parent, but other forms of intangible knowledge capital do have such an effect. 
Table 1.6 Multinomial logit estimates for intra-group transfer of technology

\begin{tabular}{|c|c|c|c|}
\hline Variables & Two-way transfer & Parent-affiliate only & Affiliate-parent only \\
\hline \multirow[t]{2}{*}{ Turnover } & 0.08 & -0.19 & 1.04 \\
\hline & $(0.52)$ & $(0.47)$ & $(0.96)$ \\
\hline \multirow[t]{2}{*}{ Turnover squared } & -0.02 & -0.00 & -0.04 \\
\hline & $(0.02)$ & $(0.02)$ & $(0.04)$ \\
\hline \multirow[t]{2}{*}{ Tangible fixed assets } & 0.15 & 0.09 & -0.29 \\
\hline & $(0.10)$ & $(0.06)$ & $(0.14)^{* *}$ \\
\hline \multirow[t]{2}{*}{ Intangible fixed assets } & 0.02 & 0.02 & 0.27 \\
\hline & $(0.03)$ & $(0.03)$ & $(0.08)^{* * *}$ \\
\hline \multirow[t]{2}{*}{$R \& D$ expenditure } & 0.05 & -0.15 & -0.01 \\
\hline & $(0.04)$ & $(0.05)^{* * *}$ & $(0.06)$ \\
\hline \multirow[t]{2}{*}{ Total factor productivity } & 0.42 & 0.50 & -0.87 \\
\hline & $(0.34)$ & $(0.31)^{*}$ & $(0.48)^{*}$ \\
\hline \multirow[t]{2}{*}{ Profitability } & -2.01 & -1.22 & 4.48 \\
\hline & $(1.39)$ & $(1.48)$ & $(1.49)^{* * *}$ \\
\hline \multirow[t]{2}{*}{ Total exports } & 0.10 & -0.11 & 0.29 \\
\hline & $(0.05)^{*}$ & $(0.06)^{*}$ & $(0.12)^{* *}$ \\
\hline \multirow[t]{2}{*}{ Total imports } & -0.01 & 0.05 & -0.14 \\
\hline & $(0.05)$ & $(0.06)$ & $(0.07)^{*}$ \\
\hline \multirow[t]{2}{*}{ Intra-firm exports } & 0.02 & 0.08 & 0.03 \\
\hline & $(0.04)$ & $(0.05)$ & $(0.06)$ \\
\hline \multirow[t]{2}{*}{ Intra-firm imports } & 0.13 & 0.17 & 0.10 \\
\hline & $(0.04)^{* * *}$ & $(0.04)^{* * *}$ & $(0.07)$ \\
\hline \multicolumn{4}{|l|}{ Industry-Country dummies } \\
\hline \multirow[t]{2}{*}{ HTI } & 0.83 & 0.95 & 1.71 \\
\hline & $(0.40)^{* *}$ & $(0.42)^{* *}$ & $(0.83)^{* *}$ \\
\hline \multirow[t]{2}{*}{ MHTI } & 0.66 & 0.83 & 1.18 \\
\hline & $(0.30)^{* *}$ & $(0.32)^{* * *}$ & $(0.70)^{*}$ \\
\hline \multirow[t]{2}{*}{ MLTI } & 0.45 & 0.68 & 1.99 \\
\hline & $(0.32)$ & $(0.34)^{* *}$ & $(0.74)^{* * *}$ \\
\hline \multirow[t]{2}{*}{ HTKIS } & 1.59 & 1.13 & 1.68 \\
\hline & $(0.40)^{* * *}$ & $(0.42)^{* * *}$ & $(0.97)^{*}$ \\
\hline \multirow[t]{2}{*}{ US } & 0.75 & 0.29 & -0.29 \\
\hline & $(0.34)^{* *}$ & $(0.33)$ & $(0.58)$ \\
\hline \multirow[t]{2}{*}{$\mathrm{EU}$} & 0.72 & 0.22 & 0.12 \\
\hline & $(0.30)^{* *}$ & $(0.28)$ & $(0.48)$ \\
\hline \multirow[t]{2}{*}{ Japan } & 0.93 & 1.54 & -34.41 \\
\hline & $(0.89)$ & $(0.80)^{* *}$ & $(-2.46)^{* * *}$ \\
\hline \multirow[t]{2}{*}{ Constant } & -4.58 & -1.40 & -11.07 \\
\hline & $(2.43)^{*}$ & (2.19) & $(4.65)^{* *}$ \\
\hline Number of observations & 760 & & \\
\hline Obs in each quadrant & 236 & 190 & 47 \\
\hline Log pseudo-likelihood & \multicolumn{2}{|c|}{-825.83} & \\
\hline Wald $\chi^{2}(54)$ & \multicolumn{2}{|c|}{2827.00} & \\
\hline Prob $>\chi^{2}$ & \multicolumn{2}{|c|}{0.00} & \\
\hline Pseudo $R^{2}$ & \multicolumn{2}{|c|}{0.13} & \\
\hline
\end{tabular}

Notes: $*, * * * * *$ significant at the $10 \%, 5 \%$ and $1 \%$ level, respectively

Robust standard errors in brackets 
Trade intensity also plays a role in explaining intra-firm technology and managerial knowledge transfer. Export intensity in general is associated with technology sourcing behaviour, suggesting that export-intensive plants are able to develop capabilities which in turn are able to develop into a source of technology flows back to the parent enterprise. This effect is restricted to technology flows, however. There is also a positive relationship between two-way knowledge flows (of both types) and exporting. There is therefore some support for H5. Because of the extensive evidence of endogeneity between exporting, productivity and $\mathrm{R} \& \mathrm{D} /$ innovation (Wagner 2007), one has to be cautious about inferring causality from correlation here: it is possible that exporting and technology flows are both determined by some other factor not accounted for in the model. However, the fact that export intensity is also negatively correlated with parent-affiliate knowledge exploiting flows (both technology and managerial) tends to suggest that export-intensive MNE affiliates in Italy are markedly more likely to be a source of technology or knowledge flows to their parent than to be the recipient of such flows, consistent with the learning-by-exporting hypothesis.

In terms of the conditioning variables, there is no effect of affiliate size in any of the estimations. It is interesting, however, to contrast the coefficients on the two measures of performance. In Table 1.6, for example, the productivity of the affiliate is only weakly related to technology flows, and indeed in the case of affiliate-parent flows, this is a negative relationship. However, the corresponding effect of profitability is positive and significant. This suggests that parents are more likely to source technology from profitable affiliates, rather than from productive ones.

There are also some marked differences in technology transfer behaviour among affiliates of different nationalities (Table 1.6). Specifically, Japanese affiliates are extremely unlikely to exhibit affiliate-parent technology sourcing behaviour compared with those from the US or EU, and more likely to exhibit technology exploiting behaviour. Affiliates from the latter two regions exhibit similar technology transfer patterns to each other, with two-way technology flows being significantly more likely among US and EU subsidiaries than among those from Japan. Intriguingly, these marked national differences are restricted to technology transfer; there is no evidence of any national variations in the patterns of managerial knowledge flows (Table 1.7). 
Table $1.7 \quad$ Multinomial logit estimates for intra-group transfer of managerial and other competencies

\begin{tabular}{|c|c|c|c|}
\hline Variables & Two-way transfer & Parent-affiliate only & Affiliate-parent only \\
\hline \multirow[t]{2}{*}{ Turnover } & -0.39 & 0.37 & 0.14 \\
\hline & $(0.43)$ & $(0.46)$ & $(0.82)$ \\
\hline \multirow[t]{2}{*}{ Turnover squared } & 0.02 & -0.02 & 0.00 \\
\hline & $(0.02)$ & $(0.02)$ & $(0.04)$ \\
\hline \multirow[t]{2}{*}{ Tangible fixed assets } & 0.02 & -0.01 & -0.14 \\
\hline & $(0.06)$ & $(0.05)$ & $(0.09)$ \\
\hline \multirow[t]{2}{*}{ Intangible fixed assets } & 0.01 & -0.00 & 0.11 \\
\hline & $(0.03)$ & $(0.03)$ & $(0.06)^{* *}$ \\
\hline \multirow[t]{2}{*}{$R \& D$ expenditure } & 0.01 & -0.02 & -0.03 \\
\hline & $(0.04)$ & $(0.04)$ & $(0.06)$ \\
\hline \multirow[t]{2}{*}{ Total factor productivity } & 0.54 & -0.10 & -0.35 \\
\hline & $(0.28)^{* *}$ & $(0.28)$ & $(0.39)$ \\
\hline \multirow[t]{2}{*}{ Profitability } & -2.31 & 1.84 & 2.02 \\
\hline & $(1.41)^{*}$ & $(0.99)^{*}$ & $(1.27)$ \\
\hline \multirow[t]{2}{*}{ Total exports } & 0.09 & -0.09 & 0.14 \\
\hline & $(0.05)^{*}$ & $(0.05)^{*}$ & $(0.12)$ \\
\hline \multirow[t]{2}{*}{ Total imports } & -0.01 & 0.01 & -0.08 \\
\hline & $(0.04)$ & $(0.06)$ & $(0.08)$ \\
\hline \multirow[t]{2}{*}{ Intra-firm exports } & 0.06 & 0.08 & 0.08 \\
\hline & $(0.03)^{*}$ & $(0.05)^{*}$ & $(0.07)$ \\
\hline \multirow[t]{2}{*}{ Intra-firm imports } & 0.06 & 0.11 & 0.06 \\
\hline & $(0.03)^{*}$ & $(0.04)^{* *}$ & $(0.07)$ \\
\hline \multicolumn{4}{|l|}{ Industry-Country dummies } \\
\hline \multirow[t]{2}{*}{ HTI } & 0.26 & 0.58 & -0.86 \\
\hline & $(0.38)$ & $(0.41)$ & $(0.83)$ \\
\hline \multirow[t]{2}{*}{ MHTI } & 0.43 & 0.60 & 0.36 \\
\hline & $(0.29)$ & $(0.32)^{*}$ & $(0.51)$ \\
\hline \multirow[t]{2}{*}{ MLTI } & 0.82 & 1.08 & 0.73 \\
\hline & $(0.31)^{* * *}$ & $(0.34)^{* * *}$ & $(0.56)$ \\
\hline \multirow[t]{2}{*}{ HTKIS } & 0.71 & 0.50 & -0.95 \\
\hline & $(0.38)^{*}$ & $(0.40)$ & $(1.22)$ \\
\hline \multirow[t]{2}{*}{ US } & 0.34 & 0.21 & 0.01 \\
\hline & $(0.32)$ & $(0.33)$ & $(0.51)$ \\
\hline \multirow[t]{2}{*}{$\mathrm{EU}$} & 0.39 & 0.17 & -0.61 \\
\hline & $(0.27)$ & $(0.28)$ & $(0.48)$ \\
\hline \multirow[t]{2}{*}{ Japan } & -0.32 & 0.25 & 0.33 \\
\hline & $(0.72)$ & $(0.68)$ & $(0.89)$ \\
\hline \multirow[t]{2}{*}{ Constant } & -0.28 & -3.36 & -4.36 \\
\hline & $(2.05)$ & $(2.17)$ & $(3.82)$ \\
\hline Number of observations & 760 & & \\
\hline Obs in each quadrant & 270 & 195 & 45 \\
\hline Log pseudo-likelihood & \multicolumn{2}{|c|}{-873.51} & \\
\hline Wald $\chi^{2}(54)$ & \multicolumn{2}{|c|}{157.70} & \\
\hline Prob $>\chi^{2}$ & \multicolumn{2}{|c|}{0.00} & \\
\hline Pseudo $R^{2}$ & \multicolumn{2}{|c|}{0.08} & \\
\hline
\end{tabular}

Notes: $*, * * * * *$ significant at the $10 \%, 5 \%$ and $1 \%$ level, respectively

Robust standard errors in brackets 


\section{DISCUSSION AND CONCLUSIONS}

The purpose of this chapter is to help open the 'black box 'of international knowledge transfer, and so contribute to the developing theoretical perspective of MNEs as a source of knowledge flows. The dominant paradigm is of the technologically superior MNE transferring knowledge to its foreign affiliates, with subsequent diffusion to the host economy. Although questions have been raised about this paradigm from a conceptual perspective, most empirical evidence questioning it comes from an indirect methodology, often inferring intra-firm technology flows from their effects on host country productivity and growth. This analysis has instead looked for direct evidence of intra-firm knowledge flows, and related these flows to intra-firm trade and other affiliate characteristics. The dataset is unique, first in being designed specifically for the purpose of identifying different types of knowledge flows within MNEs, and second in being based on an official survey carried out by a national statistical agency.

There are a number of key findings. First, there is clear evidence of very substantial knowledge flows between MNE parent companies and their Italian-based affiliates. Although knowledge flows from parent to affiliates are common, there is also evidence of extensive flows in the reverse direction, often as part of a two-way transfer. Unlike most studies, which concentrate on technology, we find that broadly similar patterns of flows exist for both technology and managerial knowledge.

Second, intra-firm trade and intra-firm knowledge flows are strongly related. Affiliates which are embedded into the parents' (physical) supply chain are more likely to receive and impart flows of new knowledge than those which are not. This suggests that the strong link identified between international flows of trade and knowledge noted in the economics literature (e.g. van Pottelsberghe de la Potterie and Lichtenberg 2001) is also a feature of knowledge and trade flows that take place within MNEs. This is consistent with the conceptual analysis of Davidson and McFetridge (1985) on the transfer of core technologies within the firm, especially since there is an absence of any relationship between technology-sourcing subsidiaries and intra-firm trade.

Third, affiliates' intangible capital intensity is strongly linked to 'reverse' knowledge flows from affiliates to parents. However, affiliate R\&D capacity has no such effect after the intra-firm trade effect is allowed for. This appears to suggest that, at least for this sample of foreign affiliates in Italy, technology and managerial knowledge flows running from affiliates to their parents (and other units of the enterprise) are unlikely to flow directly from the technology developed within the affiliate by its R\&D efforts, but indirectly from knowledge absorbed from elsewhere. This does imply a degree of technology sourcing by such subsidiaries.

Fourth, export intensity is associated both with a greater likelihood of affiliate-parent technology transfer and with a reduced likelihood of (one-way) parent-affiliate flows. This suggests that being exposed to external markets enhances the capabilities of the subsidiary, and makes it less (technologically) dependent on the parent organisation.

Finally, country of ownership matters in intra-firm technology transfer, but not in other forms of managerial knowledge flows. Specifically, Japanese affiliates are much more likely than those with European or American parents to have traditional parent-affiliate technology transfer, and are very unlikely to exhibit reverse transfer from affiliates to parents.

In terms of MNE theory, there is both comfort and a degree of concern in the findings. In aggregate, there is certainly support for the traditional model of the MNE as a vehicle for the international transfer of technology. Much of the overall flow of knowl- 
edge between MNEs and their affiliates runs from parents to affiliates. This is consistent with the role of the hierarchy in general, and MNEs in particular, as a superior vehicle of knowledge transfer and diffusion with respect to arm's length market forces under uncertainty and other market failures conditions. In addition, the fact that we find substantial evidence of the transfer of managerial competencies, while much of the FDI literature focuses exclusively on technology transfer and spillovers, is consistent with the standard theoretical framework of the superior ownership advantage held by MNEs. Nevertheless, the results detailed above clearly show that the model of the MNE as an international conduit of technology and knowledge does not hold everywhere and always. Around one third of surveyed affiliates received no form of technological or managerial knowledge flows from their parent. While these findings do not suggest that the theory of the MNE is fundamentally deficient, they do indicate the value of obtaining direct evidence on the nature and extent of knowledge flows to test the validity of established theory, and to determine the conditions under which theory does or does not hold. Here, our findings on the factors associated with different types of knowledge flows are relevant. In addition, the findings that affiliate-parent (especially two-way) knowledge transfer is commonplace supports the suggestion that knowledge sourcing is an important determinant of FDI, especially between advanced industrialised countries.

More generally, the evidence provided on the multidirectional and multifaceted nature of knowledge flows between parent companies and foreign affiliates might stimulate the development of a more articulated theoretical framework to examine MNE knowledge creation and transfer behaviour. This extended theoretical framework could usefully acknowledge that there is a great deal of complexity and heterogeneity in MNE knowledge transfer behaviour. Such an extended theory would also help in understanding the existence of cumulative processes spurred by virtuous circles of knowledge creation and transfers between the parent company, the foreign affiliate and domestic companies. In contrast, we should recognise that vicious circles can also occur, even in the presence of relevant 'static' one-way knowledge transfer, where subsequent diffusion to the domestic sector never occurs.

There are also managerial implications from this research. The first is that truly global integration involves consideration of both intra-firm physical (trade) as well as knowledge flows between MNE headquarters and subsidiaries. The fact that the link between intra-firm trade and knowledge flows is even stronger for managerial knowledge than for flows of technology also indicates support for the conceptual positions of Kobrin (1991) and Feinberg and Gupta (2004) on the nature of global integration within the MNE: intra-firm trade requires the existence of relatively well developed communication and knowledge-exchange structures within the MNE. Second, the results suggest that if MNEs want to engage in technology sourcing from subsidiary locations, building up the intangible capital of subsidiaries rather than their R\&D capacity might be the way forward. This chimes with the analysis of Asmussen et al. (2013) who find not only that the internal and externally sourced knowledge of MNE subsidiaries interact, but that it takes balance between the extent of internal and external knowledge for effective knowledge transfer from and between subsidiaries to occur. Our research suggests that knowledge embedded in intangible assets as well as R\&D stock may have a role to play in this interaction and balancing process. Finally, the fact that affiliate productivity is weakly linked to technology flows while affiliate profitability is strongly linked to such flows is intriguing from the MNE's perspective. This result supports the concepts of embeddedness and internalisation, in that affiliates which make a greater contribution to financial perfor- 
mance have better links to the parent. At the same time, financial performance of affiliates may result from any number of factors, such as transfer pricing, or the market structure in the host country, and may be independent of technological or managerial competence. In contrast, affiliates that are more productive (that is, make better use of internal resources) may also be good sources of technology for the parent, but the parent fails to capture this in terms of knowledge flows.

From the perspective of the future development of this stream of research, it is useful to point out the limitations of our work. First, the key questions on international technology and knowledge transfer are discrete in nature. We do not observe the strength or longevity of the knowledge flows, simply whether they occur. A future development would be to determine the importance of thresholds of the scale and scope of these transfers for facilitating knowledge development within the host or home country. Second, the data derive from affiliates of MNEs located in a single country, and we must acknowledge the possibility that there is some Italy-specific element to our findings. Third, in common with all cross-sectional datasets, even those backed by official sanction, we must be very cautious in imputing any degree of causation into the correlations between dependent and independent variables. Finally, the magnitude of any spillovers or productivity growth effects from these knowledge transfers are not measured. A key development in this area will be to couple direct survey evidence of this type to research on the motivation of FDI and its productivity effects. This would provide a powerful insight into the links between the motive for FDI, the capacity of firms to manage knowledge or technology flows, and the effects of MNEs on the host economy.

\section{NOTES}

1. Figure 1.1 does not purport to be a complete representation of potential knowledge flows involving MNEs and the domestic economy. Notably, it excludes knowledge flows and spillovers within the foreign-owned and domestic-owned sectors respectively. For an analysis of productivity spillovers within the foreign-owned sector of UK manufacturing see Driffield and Love (2005).

2. Note that Feinberg and Gupta (2004) posit this relationship between intra-firm trade and knowledge flows on the understanding that such a link indicates the ability of the MNE to absorb and utilise the R\&D output and knowledge sourced by its subsidiary. Implicitly, therefore, they expect intra-firm trade to be linked positively to affiliate-parent technology sourcing knowledge flows, although such a link is not tested.

3. Harzing and Noorderhaven found stronger results for subsidiary intra-firm imports than for intra-firm exports.

4. Parent companies from the US, EU and Japan are separately identified, as these account for $85 \%$ of observations.

5. Micro-data used in this study refer to the Official Survey on foreign affiliates in Italy, carried out by the Italian National Statistical Institute (ISTAT) from 2005-2006. Qualitative questions on knowledge transfer were introduced following OECD recommendations to increase the stock of available information on MNE behaviour. Aggregated figures were disseminated by ISTAT in February 2007, while micro-data were made available for research purposes shortly after. The dataset used in this study can be accessed upon request at the ADELE laboratory located in the headquarters of ISTAT in Rome.

6. The reasons for concentrating this study on manufacturing and HTKIS companies are twofold. First, the focus of the research is on industries with a clear relevance of technology as a driver of the industry, this is clearly beyond the scope of most traditional service industries (dominated by, for example, retailing and wholesaling), where international intra-firm technological transfer is not a significant feature. Second, some firm level performance indicators, such as TFP and profitability, 
could not be calculated with respect to most of the service industries, partly because of data constraints and also because TFP is not a particularly meaningful indicator for most traditional service sectors.

7. Scientific and technological knowledge can be embedded in material goods, formally incorporated in patents, licences or software, or stem from R\&D, innovation or project activities. This is distinct from managerial competencies, including new managerial procedures or strategies. Note that the question allows for transfer to/from the Italian affiliate from/to any part of the MNE group, not merely headquarters.

8. Managerial, commercial and other types of competencies may include the adoption of new managerial procedures or strategies, in general or with respect to specific business functions: accounting, commercial, legal, and logistics.

9. Log-odds ratios are the standard manner of reporting the results of a MNLM, and refer to differences in the odds ratios between the considered modality and the baseline modality, or $\mathrm{P}(\mathrm{E}) /(1-\mathrm{P}(\mathrm{E}))$. They can also be interpreted as differences in probability. In this respect, log-odds ratios are particularly close to standard regression coefficients, since they assess the sign and magnitude of the covariate (marginal) effect on the 'relative' probability of the relevant event.

10. The coefficients on intra-firm exports for Types 1 and 2 in Table 1.6 are positive but insignificant.

\section{REFERENCES}

Almeida P (1996) 'Knowledge sourcing by foreign multinationals: Patent citation analysis in the US semiconductor industry', Strategic Management Journal, 17 (Special issue), 155-165.

Andersson U, Bjorkman I and Forsgren M (2005) 'Managing subsidiary knowledge creation: The effect of control mechanisms on subsidiary local embeddedness', International Business Review 14, $521-538$.

Andersson U, Forsgren M, and Holm U (2001) 'Subsidiary embeddedness and competence development in MNCs - a multi-level analysis', Organization Studies, 22, 1013-1034.

Andersson U, Forsgren M and Holm U (2007) 'Balancing subsidiary influence in the federative MNC: a business network view', Journal of International Business Studies, 38, 802-818.

Asmussen C G, Foss N J and Pedersen T (2013) 'Knowledge transfer and accommodation effects in multinational corporations: Evidence from European subsidiaries', Journal of Management, 39, $1397-1429$.

Aw B Y, Roberts M J and Xu D Y (2008) 'R\&D investments, exporting, and the evolution of firm productivity', American Economic Review, 98, 451-456.

Bell M and Marin A (2004) 'Where do foreign direct investment-related technology spillovers come from in emerging economies? An exploration of Argentina in the 1990s', European Journal of Development Research, 16, 653-686.

Bernard A B, Jensen J B, Redding S J and Schott P K (2010) 'Intra-firm trade and product contractibility', NBER Working Paper No. 15881.

Birkinshaw J and Morrison A J (1995) 'Configurations of strategy and structure in subsidiaries of multinational corporations', Journal of International Business Studies, 26, 729-754.

Buckley P J and Casson M C (1976) The Future of the Multinational Enterprise, London: Macmillan.

Cantwell J (2009) 'Location and the multinational enterprise', Journal of International Business Studies, $40,35-41$.

Cantwell J and Janne O (1999) 'Technological globalisation and innovation centres: The role of technological leadership and location hierarchy', Research Policy, 28, 119-144.

Caves R E (1986) Multinational Enterprise and Economic Analysis, Cambridge: Cambridge University Press.

Cho K R (1990) 'The role of product-specific factors in intra-firm trade of US manufacturing multinational corporations', Journal of International Business Studies, 21, 319-330.

Ciabuschi F, Dellestrand H and Martin O M (2011) 'Internal embeddedness, headquarters involvement, and innovation importance in multinational enterprises', Journal of Management Studies, 48, $1612-1639$. 
Cohen W M and Levinthal D A (1989) 'Innovation and learning: The two faces of R\&D', Economic Journal, 99(397), 569-596.

Davidson W H and McFetridge D G (1985) 'Key characteristics in the choice of international technology transfer mode', Journal of International Business Studies, Summer, 2, 5-21.

Driffield N and Love J H (2003) 'FDI, technology sourcing and reverse spillovers', The Manchester School, 71, 659-672.

Driffield N and Love J H (2005) 'Who gains from whom? Spillovers, competition and technology sourcing in the foreign-owned sector of UK manufacturing', Scottish Journal of Political Economy, $52,663-686$.

Driffield N, Love J H and Menghinello S (2010) 'The multinational enterprise as a source of international knowledge flows: Direct evidence from Italy', Journal of International Business Studies, 41, 350-359.

Driffield N, Love J H and Yang Y (2016) 'Reverse international knowledge transfer in the MNE: (Where) does affiliate performance boost parent performance?', Research Policy, 45, 491-506.

Driffield N, Munday M and Roberts A (2002) 'Foreign direct investment, transactions linkages, and the performance of the domestic sector', International Journal of the Economics of Business, 9, 335-351.

Dunning J H (1979) 'Explaining patterns of international production: In defence of the eclectic theory', Oxford Bulletin of Economics and Statistics, 41, 269-295.

Feinberg S E and Gupta A K (2004) 'Knowledge spillovers and the assignment of R\&D responsibilities to foreign subsidiaries', Strategic Management Journal, 25, 823-845.

Gupta A K and Govindarajan V (1991) 'Knowledge flows and the structure of control within multinational corporations', Academy of Management Review, 13, 768-792.

Gupta A K and Govindarajan V (1994) 'Organizing for knowledge flows within MNCs', International Business Review, 43, 443-457.

Harzing A-W K and Noorderhaven N (2006) 'Knowledge flows in MNCs: An empirical test and extension of Gupta and Govindarajan's typology of subsidiary roles', International Business Review, 15, $195-214$.

Hausman J and McFadden D (1984) 'Specification tests for the multinomial logit model', Econometrica, $52,1219-1240$.

Ito B and Wakasugi R (2007) 'What factors determine the mode of overseas R\&D by multinationals? Empirical evidence', Research Policy, 36, 1275-1287.

Kobrin S J (1991) 'An empirical analysis of the determinants of global integration', Strategic Management Journal, Summer Special Issue 12, 17-32.

Kotabe M, Dunlap-Hinkler D, Parente R and Mishra H A (2007) 'Determinants of cross-national knowledge transfer and its effect on firm innovation', Journal of International Business Studies, 38, 259-282.

Marin A and Bell M (2006) 'Technology spillovers from foreign direct investment (FDI): The active role of MNC subsidiaries in Argentina in the 1990s', Journal of Development Studies, 42, 678-697.

Marin A and Bell M (2010) 'The local/global integration of MNC subsidiaries and their technological behaviour: Argentina in the late 1990s', Research Policy, 39, 919-931.

Marin A and Giuliani E (2011) 'MNC subsidiaries' position in global knowledge networks and local spillovers: Evidence from Argentina', Innovation and Development, 1, 91-114.

McFadden D K, Train K and Tye W B (1976), 'An application of diagnostic tests for the independence from irrelevant alternatives property of the multinomial logit model', Transportation Research Record, 637, 39-45.

McGuinness M, Demirbag M and Bandara S (2013) 'Towards a multi-perspective model of reverse knowledge transfer in multinational enterprises: A case study of Coats PLC', European Management Journal, 31, 179-195.

Meyer K and Sinani E (2009) 'When and where does foreign direct investment generate positive spillovers? A meta-analysis', Journal of International Business Studies, 40, 1075-1094.

Michailova S and Mustaffa Z (2012) 'Subsidiary knowledge flows in multinational corporations: Research accomplishments, gaps and opportunities', Journal of World Business, 47, 383-396.

Mudambi R and Navarra P (2004) 'Is knowledge power? Knowledge flows, subsidiary power and rent-seeking within MNCs', Journal of International Business Studies, 35, 385-406.

Niosi J (1999) 'The internationalization of industrial R\&D: From technology transfer to the learning organization', Research Policy, 28, 107-117. 
Oh K-S and Anchor J (2017) 'Factors affecting reverse knowledge transfer from subsidiaries to multinational companies: Focusing on the transference of local market information', Canadian Journal of Administrative Sciences, 34, 329-342.

Pearce R D (1999) 'Decentralised R\&D and strategic competitiveness: Globalised approaches to generation and use of technology in multinational enterprises (MNEs)', Research Policy, 28, 157-178.

Phene A and Almeida P (2008) 'Innovation in multinational subsidiaries: The role of knowledge assimilation and subsidiary capabilities', Journal of International Business Studies, 39, 901-919.

Rabiosi L (2011) 'Subsidiary roles and reverse knowledge transfer: An investigation of the effects of coordination mechanisms', Journal of International Management, 17, 97-113.

Rabiosi L and Santangelo G D (2013) 'Parent company benefits from reverse knowledge transfer: The role of the liability of newness in MNEs', Journal of World Business, 48, 160-170.

Serapio M G and Dalton D H (1999) 'Globalization of industrial R\&D: An examination of foreign direct investments in R\&D in the United States', Research Policy, 28, 303-316.

Singh J (2007) 'Asymmetry of knowledge spillovers between MNCs and host country firms', Journal of International Business Studies, 38, 764-786.

Small K and C Hsiao (1985) 'Multinomial logit specification tests', International Economic Review, 26, 619-627.

Smeets R (2008) 'Collecting the pieces of the FDI knowledge spillovers puzzle', World Bank Research Observer, 23, 107-138.

van Pottelsberghe de la Potterie B and Lichtenberg F (2001) 'Does foreign direct investment transfer technology across borders?', Review of Economics and Statistics, 83, 490-497.

Veugelers R and Cassiman B (2004) 'Foreign subsidiaries as a channel of international technology diffusion: Some direct firm level evidence from Belgium', European Economic Review, 48, 455-476.

Wagner J (2007) 'Exports and productivity: a survey of the evidence from firm-level data', The World Economy, 30, 60-82. 